\title{
Variations in vascular endothelial growth factor levels during ovarian superovulation and reduction of ovarian hyperstimulation incidence in young women: A prospective study
}

\author{
Eliahu Levitas $^{\mathbf{1}^{*}}$, M. Huleihal ${ }^{2}$, E. Lunenfeld ${ }^{1}$, R. Gakman ${ }^{1}$, M. Friger ${ }^{3}$, G. Potashnik ${ }^{1}$ \\ ${ }^{1}$ Fertility and IVF Unit, Department of Obstetrics and Gynecology, Soroka University Medical Center, Beer-Sheva, Israel \\ ${ }^{2}$ Department of Immunology, Faculty of Health Sciences, Ben-Gurion University of the Negev, Beer-Sheva, Israel \\ ${ }^{3}$ Department of Epidemiology, Faculty of Health Sciences, Ben-Gurion University of the Negev, Beer-Sheva, Israel \\ Email: ${ }^{\text {Levitase@bgu.ac.il }}$
}

Received 13 December 2012; revised 16 January 2013; accepted 25 January 2013

\begin{abstract}
Variations in Vascular Endothelial Growth Factor (VEGF) levels were prospectively evaluated in 18 young women undergoing in vitro fertilization treatments according to the "Long Protocol" and a typical pattern of VEGF levels was recorded. A significant increase in VEGF concentrations was observed only when the follicles reached a mean diameter of $\mathbf{1 5 . 3}$ $\mathrm{mm}$ in concurrence with mature oocyte retrieval. Since an increase in VEGF levels is related to follicular vascularity and oocyte developpment, our study supports the approach that oocyte retrieval may be performed when follicles $>15 \mathrm{~mm}$ in diameter appear. Anticipating egg retrieval in young patients with an optimal ovarian reserve may decrease the incidence of severe ovarian hyperstimulation, without compromising the treatment results.
\end{abstract}

Keywords: Vascular Endothelial Growth Factor (VEGF); In Vitro Fertilization; Gonadotropin Stimulation; Follicle Size; Prevention of Ovarian Hyperstimulation

\section{INTRODUCTION}

The incidence of severe Ovarian Hyperstimulation Syndrome (OHSS) in gonadotropin-treated cycles is $0.5 \%$ $3.0 \%$ [1]. Among high risk women the incidence approaches $20 \%$ [2]. OHSS is a reproductive disorder associated with dysfunctional vascularization. In an animal model, rat ovaries hyperstimulated in vivo using gonadotropins plus human Chorionic Gonadotropin (hCG) demonstrated increased vascular permeability, which was reversed by administration of a specific Vascular Endothelial Growth Factor (VEGF) inhibitor [3] or by block-

\footnotetext{
"Corresponding author.
}

ing expression of VEGF receptor using a dopamine agonist [4]. As well, during the luteal phase, inhibition of VEGF precipitates a suppression of progesterone secretion pointing to additional roles for VEGF in the ovary [5]. VEGF was found to be the key factor in OHSS development during gonadotropin treatment for infertility $[6,7]$.

VEGF, also known as Vascular Permeability Factor, is a homodimeric glycoprotein acting as an endothelial cell mitogenic/angiogenic factor [8] and as a permeability factor [9]. It is able to induce proliferation of endothelial cells and their organization into a new vascular network, thus supplying blood rich in oxygen, nutrients, hormones, and various growth factors [10]. The balance of VEGF isoforms control follicle progression and luteogenesis [11].

\section{DISCUSSION}

In situ hybridization technique has been able to reveal the presence of VEGF mRNA in rat corpora lutea and cumulus oophorus of preovulatory follicles [12]. Distribution of VEGF receptor in endothelial cells of follicles has been demonstrated by in situ hybridization [13] and immunocytochemistry [14]. Ovarian VEGF gene expression was found to increase significantly following hCG injection in gonadotropin-treated animals, and according to studies in vivo and in vitro, ovarian granulosa cells express VEGF mRNA in a time- and dose-dependent manner [15]. Therefore, reduction of gonadotropin stimulation time to the minimum necessary may have a positive impact in terms of reducing the incidence of severe OHSS.

Serum VEGF concentrations are positively correlated with follicular fluid VEGF levels [16]. Therefore we sought to determine whether variations in VEGF secretion 
during gonadotropin stimulation correlated to the follicular size and estradiol levels may reflect follicular maturity for egg retrieval and reduce to minimum the duration and magnitude of gonadotropin stimulation in IVF patients with the purpose to decrease the incidence of OHSS in a group of young patients with an optimal ovarian reserve [17] without compromising treatment success. The relationship between serum VEGF and oocytes retrieved, fertilization, implantation, and pregnancy rates were investigated.

This prospective study was approved by the Institutional Review Board at the Soroka University Medical Center, Beer-Sheva, Israel, and included 18 young patients undergoing IVF due to male infertility (9 cases), pelvic adhesions ( 2 cases), and unexplained infertility (7 couples). The mean age of the 18 women in the study was $26.9 \pm 1.7$ years and the mean basic hormonal profile on the third day of the menstrual cycle was: estradiol $26.2 \pm 26 \mathrm{pg} / \mathrm{ml}$; FSH $5.5 \pm 1.7 \mathrm{mIU} / \mathrm{ml} ; \mathrm{LH} 4.8 \pm 2.6$ $\mathrm{mIU} / \mathrm{ml}$.

The standard treatment regimen followed the "Long Protocol”, and ovarian down regulation was achieved by administration of controlled-release Gonadotropin Releasing Hormone (GnRH) agonist $3.75 \mathrm{mg}$ (Decapeptyl C.R. $3.75 \mathrm{mg}$, Ferring Farmaceutical GmbH, Kiel, Germany) at the midluteal phase of the preceding cycle. Serum estradiol $\left(E_{2}\right)$ levels below $50 \mathrm{pg} / \mathrm{mL} 12$ - 14 days following GnRH agonist injection were used to define ovarian quiescence. Controlled ovarian hyperstimulation was performed using hMG (Pergonal, Teva, Ramat-Gan, Israel) according to an individually adjusted technique monitored by serum estradiol $\left(E_{2}\right)$ and transvaginal ovarian sonography. Ten thousand Units of hCG (Chorigon, Teva, Ramat-Gan, Israel) were injected intramuscularly when serum $E_{2}$ levels were at least $500 \mathrm{pg} / \mathrm{ml}$ and at least two follicles $>15 \mathrm{~mm}$ in diameter were observed. Mean gonadotrophin stimulation period per treatment cycle was $13 \pm 0.9$ days.

Transvaginal sonographically guided ovum retrieval was performed under general anesthesia 36 - 38 hours following hCG administration. The oocytes were inseminated or subjected to intracytoplasmic sperm injection (ICSI) according to the semen quality on the day of egg retrieval. Embryo transfer (ET) was performed 2 or 3 days later using embryos with the highest number of blastomers and having the highest embryo grading score.

Luteal phase was supported by five injections of hCG $1250 \mathrm{U}$ every other day starting 48 hours after oocyte retrieval, or daily intramuscular administration of $50 \mathrm{mg}$ progesterone (Gestone, Paines \& Byrne Limited, West Byfleet, Surrey, UK) in patients at high risk for developing Ovarian Hyperstimulation Syndrome (peak $\mathrm{E}_{2}$ levels $>2000 \mathrm{pg} / \mathrm{mL}$ ), or combined luteal support, adding four injections of hCG $1250 \mathrm{U}$ every other day in progester- one-supported cycles in which the serum $\mathrm{E}_{2}$ and progesterone levels dropped sharply seven days following ET.

In all patients, serum $\beta$-hCG was obtained $14-17$ days following ET and pregnancies confirmed by the presence of a pregnancy sac and cardiac activity on sonography.

Serum samples were obtained during IVF/ET treatment at the following time points: sample 1 -ovarian down-regulation (12 - 14 days following $\mathrm{GnRH}$ agonist injection); samples 2, 3, and 4-during gonadotropin administration (follicular phase); sample 5-the day of egg retrieval; sample 6-day of ET; and samples 7, 8-seven and fourteen days following ET, respectively. The assessment of VEGF serum concentration was obtained using the Elisa Kit (VEGF Quantikine Human Immunoassay, R\&D Systems Inc., Minneapolis, MN, USA).

Statistical analysis was performed two-tailed with Chisquare or Fisher exact test. Statistical significance was assumed at a $p$ value $<0.05$.

As shown in Figure 1, a coincidence was observed between the nadir of serum $E_{2}$ level and the peak VEGF level 14 days following GnRHa injection (sample 1) with values of $29 \pm 8.6 \mathrm{pg} / \mathrm{ml}$ and $3068 \pm 3490 \mathrm{pg} / \mathrm{ml}$, respectively. The next three blood samples (samples 2-4) were drawn during the gonadotrophin treatment: 5 - 7 days, 9 11 days, and 11 - 13 days (hCG injection day) of ovarian stimulation. The mean values obtained were $E_{2} 220 \pm$ $177 \mathrm{pg} / \mathrm{ml}$ and VEGF $2353 \pm 3090 \mathrm{pg} / \mathrm{ml}$ (sample 2); $\mathrm{E}_{2}$ $427 \pm 751 \mathrm{pg} / \mathrm{ml}$ and VEGF $1982 \pm 702 \mathrm{pg} / \mathrm{ml}$ (sample 3); $\mathrm{E}_{2} 1721 \pm 860 \mathrm{pg} / \mathrm{ml}$ and VEGF $2697 \pm 2713 \mathrm{pg} / \mathrm{ml}$ (sample 4). Ovarian follicular ultrasound scanning was performed during the follicular phase of the cycle concomitantly with the blood tests (samples 2-4); the following mean follicular diameters were recorded: $12.3 \pm$ $1.5 \mathrm{~mm} ; 14.1 \pm 3.5 \mathrm{~mm}$, and $15.3 \pm 0.5 \mathrm{~mm}$, respectively.

Therefore, the follicular phase of the cycle was characterized by a gradual but statistically significant $(p<$ 0.0006) reduction of the VEGF level between sample 1 (14 days following GnRHa injection) and sample 3 (9 11 days of ovarian stimulation). Thereafter, a significant increase $(p<0.002)$ in VEGF level between sample 3 and sample 4 (11 - 13 days of stimulation-hCG injection day) in concert with a continuous increase in $E_{2}$ level and a rise in the mean follicular size from $14.1 \mathrm{~mm}$ to $15.3 \mathrm{~mm}$ were observed.

Samples 5-8 (Figure 1) were obtained during the day of egg retrieval, ET, and days 7 and 14 following the ET, respectively. The $\mathrm{E}_{2}$ and VEGF values obtained were: $1112 \pm 1108 \mathrm{pg} / \mathrm{ml}$ and $2353 \pm 3156 \mathrm{pg} / \mathrm{ml} ; 807 \pm 758$ $\mathrm{pg} / \mathrm{ml}$ and $2416 \pm 3315 \mathrm{pg} / \mathrm{ml} ; 832 \pm 955 \mathrm{pg} / \mathrm{ml}$ and 2147 $\pm 2959 \mathrm{pg} / \mathrm{ml} ; 570 \pm 1343 \mathrm{pg} / \mathrm{ml}$ and $2132 \pm 3312 \mathrm{pg} / \mathrm{ml}$, respectively. No statistically significant variations were observed between the above values, and they were unaffected by the different ovarian support protocols. 


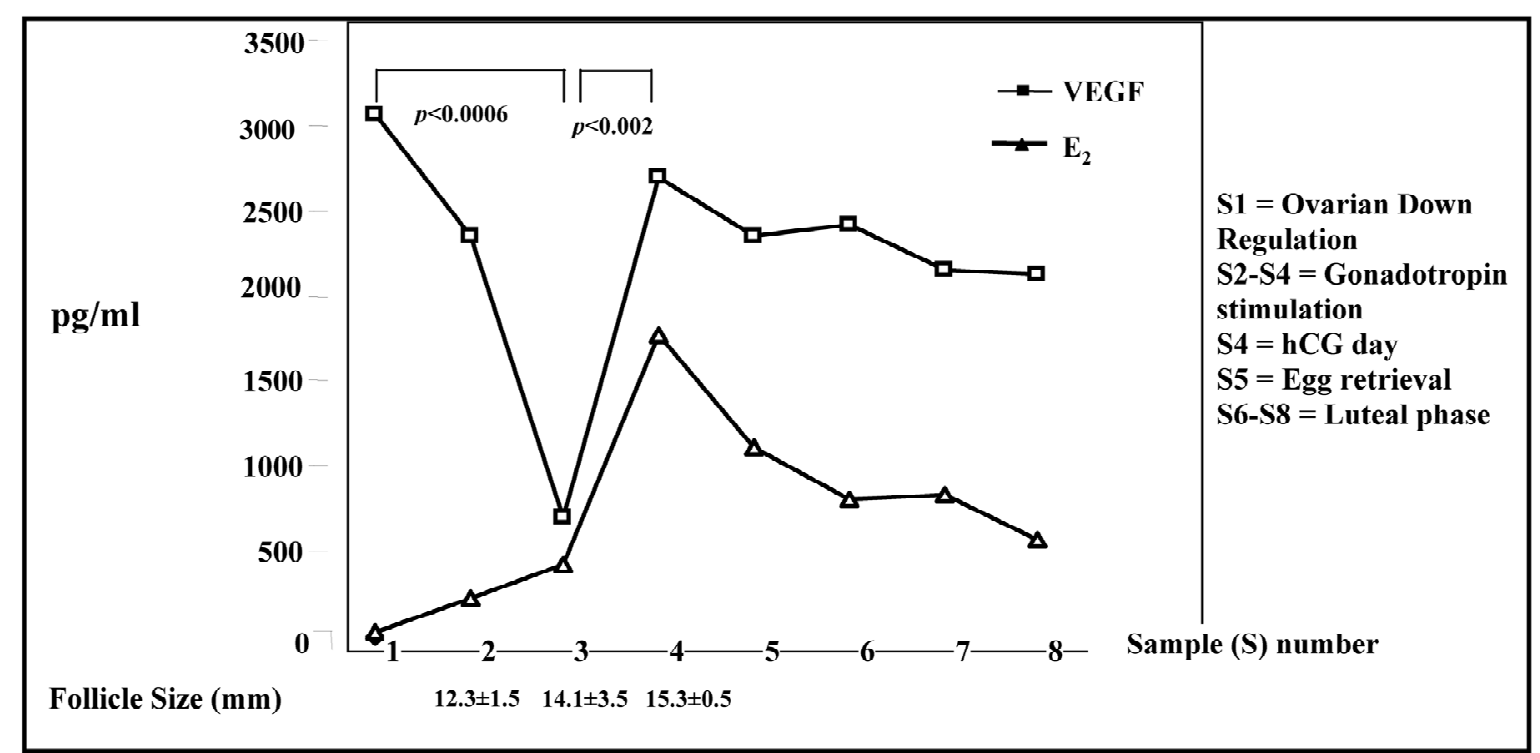

Figure 1. Estradiol $\left(\mathrm{E}_{2}\right)$ and Vascular Endothelial Growth Factor (VEGF) levels related to the size of ovarian follicles during IVF/ET treatment according to the "Long Protocol".

Embryo transfer was performed on day two or three using $3 \pm 1$ embryos per transfer. There was no difference in the number of retrieved oocytes or the fertilization rates between the study group and our general population. Three women achieved clinical pregnancy, but we could not observe a significant difference in VEGF serum levels in the pregnant women. None of the patients in the study group developed symptoms of severe OHSS.

Christenson and Stouffer [18] have been able to demonstrate that FSH-like as well as LH-like gonadotropins directly stimulate VEGF synthesis by granulosa cells and that in vivo bolus doses of r-hCG and r-hFSH were equally effective in elevating granulosa cell VEGF production. Therefore, the increase in VEGF serum concentration following GnRH agonist controlled release injection might be due to the endogenous FSH/LH search induced by the GnRH agonist acting on ovarian granulosa cells, while estradiol production was already suppressed.

Several studies have been able to demonstrate an association between increases in perifollicular blood flow on power Doppler ultrasound [19] and follicular volume on three-dimensional ultrasonography [20] with higher clinical pregnancy rates. It has already been established that as the follicle size enlarges, the follicular blood flow and follicular fluid VEGF concentrations increase significantly [21].

The timing of hCG administration that leads to the egg retrieval is typically guided by the follicle diameter and is based on the assumption that the follicular size predicts the ability of the eggs to be fertilized. The assumption is based on only a few clinical studies and recom- mends the leading follicle size of $>18 \mathrm{~mm}$ as most suitable for egg retrieval [22]. We have observed an increase in follicular size and estrogen levels induced by exogenous gonadotropin stimulation as well, but the significant elevation in VEGF level was already observed when the mean follicular diameter reached $15.3 \mathrm{~mm}$, hCG was administered and egg retrieval performed. The treatment concluded with an acceptable IVF outcome without severe ovarian hyperstimulation.

\section{CONCLUSION}

Although the oocytes from smaller follicles give lower percentages of development [23] they may allow the total number of good quality and transferable embryos to be increased [24]. We may conclude that the significant elevation in VEGF level, happening previous to hCG administration, concurrent with the increase in the mean follicle diameter to $>15 \mathrm{~mm}$ accompanied by peak estradiol levels, marks the amplifying follicular vascularity and suitability of the follicles for hCG administration and oocyte retrieval. We believe that our data support the approach that in young women with an optimal ovarian reserve cessation of gonadotropin stimulation at an earlier time should be considered. It may be of critical importance in prevention of OHSS without compromising the IVF results.

\section{REFERENCES}

[1] Vlahos, N.F. and Gregoriou, O. (2006) Prevention and management of ovarian hyperstimulation syndrome. $A n$ nals of the New York Academy of Science, 1092, 247-264. doi:10.1196/annals.1365.021 
[2] Gera, P.S., Tatpati, L.L., Allemand, M.C., Wentworth, M.A. and Coddington, C.C. (2010) Ovarian hyperstimulation syndrome: Steps to maximize success and minimize effect for assisted reproductive outcome. Fertility and Sterility, 94, 173-178.

doi:10.1016/i.fertnstert.2009.02.049

[3] Gomez, R., Simon, C., Remohi, J. and Pellicer, A. (2002) Vascular endothelial growth factor receptor-2 activation induces vascular permeability in hyperstimulated rats, and this effect is prevented by receptor blockade. Endocrinology, 143, 4339-4348. doi:10.1210/en.2002-220204

[4] Soares, S.R. (2012) Etiology of OHSS and use of dopamine agonists. Fertility and Sterility, 97, 517-522. doi:10.1016/j.fertnstert.2011.12.046

[5] Fraser, H.M. and Duncan, W.C. (2009) SEB reproduction, fertility and development award lecture 2008: Regulation and manipulation of angiogenesis in the ovary and endometrium. Reproduction, Fertility and Development, 21, 377-392. doi:10.1071/RD08272

[6] McClure, N., Healy D.L., Rogers, P.A., Sullivan, J., Beaton, L., Haning Jr., R.V., Connolly, D.T. and Robertson, D.M. (1994) Vascular Endothelial Growth Factor as capillary permeability agent in ovarian hyperstimulation syndrome. Lancet, 344, 235-236. doi:10.1016/S0140-6736(94)93001-5

[7] Wang, T.H., Horng, S.G., Chang, C.L., Wu, H.M., Tsai, Y.J., Wang, H.S. and Soong, Y.K. (2002) Human chorionic gonadotropin-induced ovarian hyperstimulation syndrome is associated with up-regulation of vascular endothelial growth factor. Journal of Clinical Endocrinology and Metabolism, 87, 3300-3308. doi:10.1210/jc.87.7.3300

[8] Ferrara, N., Houck, K., Jakeman, L. and Leung, D. (1992) Molecular and biological properties of vascular endothelial growth factor family of proteins. Endocrine Reviews, 13, 18-32.

[9] Senger, D.R., Gali, S.J., Dvorak, A.M., Perruzzi, C.A., Harvey, V.S. and Dvorak, H.F. (1983) Tumor cells secrete a vascular permeability factor that promotes accumulation of ascites fluid. Science, 219, 983-985. doi:10.1126/science.6823562

[10] Risau, W. (1997) Mechanism of angiogenesis. Nature, 386, 671-674. doi:10.1038/386671a0

[11] Qiu, Y., Seager, M., Osman, A., Castle-Miller, J., Bevan, T., Tortonese, D.J., Murphy, D., Harper, S.J., Fraser, H.M., Donaldson, L.F. and Bates, D.O. (2012) Ovarian VEGF $_{165} \mathrm{~b}$ expression regulates follicular development, corpus luteum function and fertility. Reproduction, 143, 501-511. doi:10.1530/REP-11-0091

[12] Phillips, H.S., Hains, J., Leung, D.W. and Ferrara, N. (1990) Vascular endothelial growth factor is expressed in rat corpus luteum. Endocrinology, 127, 965-967. doi:10.1210/endo-127-2-965

[13] Wulff, C., Wilson, H., Wiegand, S.J., Rudge, J.S. and Fraser, H.M. (2002) Prevention of thecal angiogenesis, antral follicular growth, and ovulation in the primate by treatment with vascular endothelial growth factor trap RIR2. Endocrinology, 143, 2797-2807. doi:10.1210/en.143.7.2797
[14] Otani, N., Sawako, M., Yamoto, M., Shikone, T., Otani, H., Nishiyama, R., Otani, T. and Nakano, R. (1999) The vascular endothelial growth factor/fms-like tyrosine kinase system in human ovary during the menstrual cycle in early pregnancy. Journal of Clinical Endocrinology and Metabolism, 84, 3845-3851. doi:10.1210/jc.84.10.3845

[15] Levitas, E., Chamoun, D., Udoff, L.C., Ando, M., Resnick, B.S. and Adashi, E.Y. (2000) Periovulatory and interleukin- $\beta$-dependent up-regulation of intraovarian vascular endothelial growth factor in the rat: Potential role for VEGF in the promotion of periovulatory angiogenesis and vascular permeability. Journal of the Society for $G y$ necologic Investigation, 7, 51-60. doi:10.1016/S1071-5576(99)00066-0

[16] Lee, A., Christenson, L.K., Stouffer, R.L., Burry, K.A. and Patton, P.E. (1997) Vascular endothelial growth factor levels in serum and follicular fluid of patients undergoing in vitro fertilization. Fertility and Sterility, 68, 305311. doi:10.1016/S0015-0282(97)81520-8

[17] Humaidan, P., Quartarolo, J., Evangelos, G. and Papanikolaou, E.G. (2010) Preventing ovarian hyperstimulation syndrome: Guidance for the clinician. Fertility and Sterility, 94, 389-340. doi:10.1016/j.fertnstert.2010.03.028

[18] Christenson, L.K. and Stouffer, R.L. (1997) Follicle-stimulating hormone and luteinizing hormone/chorionic gonadotropin stimulation of vascular endothelial growth factor production by macaque granulose cells from preand periovulatory follicles. Journal of Clinical Endocrinology and Metabolism, 82, 2135-2142. doi:10.1210/jc.82.7.2135

[19] Shrestha, S.M., Costello, M.F., Sjoblom, P., McNally, G., Bennet, M., Steigrad, S.J. and Hughes, G.J. (2006) Power doppler ultrasound assessment of follicular vascularity in the early follicular phase and its relationship with outcome of in vitro fertilization. Journal of Assisted Reproduction and Genetics, 23, 161-169. doi:10.1007/s10815-006-9029-1

[20] Merce, L.T., Bau, S., Barco, M.J., Troyano, J., Gay, R., Sotos, F. and Villa, A. (2006) Assessment of the ovarian volume, number and volume of follicles and ovarian vascularity by three-dimensional ultrasonography and power Doppler angiography on the hCG day to predict the outcome of IVF/ICSI cycles. Human Reproduction, 21, 1218-1226.

[21] Kim, K.H., Oh, D.S., Jeong, J.H., Shin, B.S., Joo, B.S. and Lee, K.S. (2004) Follicular blood flow is a better predictor of the outcome of in vitro fertilization-embryo transfer than follicular fluid vascular endothelial growth factor and nitric oxide concentrations. Fertility and Sterility, 82, 586-592. doi:10.1016/j.fertnstert.2004.02.120

[22] Salha, O., Nugent, D., Dada, T., Kaufmann, S., Levett, S., Jenner, L., Luyi, S. and Sharma, V. (1998) The relationship between follicular fluid aspirate volume and oocyte maturity in in-vitro fertilization cycles. Human Reproduction, 13, 1901-1906. doi:10.1093/humrep/13.7.1901

[23] Rosen, M.P., Shen, S.H., Dobson, A.T., Rinaudo, P.F., McCulloch, C.E. and Cedars, M.I. (2008) A quantitative assessment of follicle size on oocyte developmental competence. Fertility and Sterility, 90, 684-690. doi:10.1016/j.fertnstert.2007.02.011 
[24] Ectors, F.J., Vanderzwalmen, P., Van Hoeck, J., Nigs, M., Verhaegen, G., Delvigne, A., Schoysman, R. and Leroy, F. (1997) Relationship of human follicular diameter with oocyte fertilization and development after in-vitro fertili- zation or intracytoplasmic sperm injection. Human Reproduction, 12, 2002-2005.

doi:10.1093/humrep/12.9.2002 